\section{JIBM}

Journal of International Business and Management (JIBM) Journal Homepage: https://rpajournals.com/jibm

\title{
Diversity and Inclusion Experience of Trans Workers: The Missing Link of Trans-Friendly Environment in Organizations
}

\author{
Nusrat Hafiz" \\ Khairunnisa Mohd Azmi \\ Ariful Islam ${ }^{3}$ \\ Ahmad Shaharudin Abdul Latiff \\ Sazali Abd Wahab \\ BRAC Business School, BRAC University, Bangladesh \\ Putra Business School (PBS), University Putra Malaysia (UPM), Malaysia ${ }^{123,45}$
}

\begin{abstract}
The transgender community, one of the most marginalized communities, faces a range of discriminatory issues in workplaces and educational institutions. The study seeks to investigate the extent of organizational support ensured by the workplaces to create a transgender-friendly environment in Bangladesh. The paper opted for a mixed study and surveyed 47 trans workers using a questionnaire. The responses yielded quantitative data that was analyzed using SPSS. The qualitative data was collected through focus group discussions with seven respondents. The study findings showed that the discrimination and exclusion experience is negative for trans workers of Bangladeshi organizations and educational institutions. While most of the respondents felt primarily excluded in the formal setting, they feel that they have been intentionally left out when they meet their coworkers in informal or social gatherings. The outcomes of the discrimination involved forced termination and absenteeism on the ground of their non-binary gender identity. It was also found that many Bangladeshi organizations still do not want trans workers to represent them. To the best of researchers' understanding, the past research on the transgender community's diversity and inclusion experience in organizations is rarely covered from the developing country's perspective. This paper attempts to fulfill the study gap. Recommendations for good practices to ensure diversity is proposed to companies. Creating a more inclusive workplace is expected to create a robust economic and social impact for developing countries like Bangladesh.
\end{abstract}

Keywords: Bangladesh, Discrimination, Diversity, Inclusion, Trans workers, Transfriendly environment, Organizations

$$
\begin{gathered}
\text { *Corresponding author: Nusrat Hafiz } \\
\text { Email: } \frac{\text { nusrat.hafiz@,bracu.ac.bd; nusrat.phd mgt18@grad.putrabs.edu.my }}{\text { DOI: } \underline{\text { https://doi.org/10.37227/JIBM-2022-01-5293 }}}
\end{gathered}
$$

\section{Introduction}

In dynamic business environments, the employees at different organizations experiencing greater diversity \& inclusion (D\&I) are more likely to perform better than those not open to a diverse culture. D\&I is a critical component in fostering creativity, driving innovation, guiding business strategies, capturing new customers, and beating competitors. The concept has been rapidly evolving from 
maintaining a heterogeneous workforce to creating distinguished business practices and achieving a competitive advantage in the marketplaces. Diverse voices encourage new ideas and out-of-the-box thinking. Adding diverse voices can also help meet the requirement of a skilled workforce in developing nations. Transgender inclusion has been an untapped feat in this regard. In the COVID19 era, businesses need to prioritize their efforts to stay committed to their D\&I efforts and play a crucial role in shaping the lives of trans workers more than ever before (Out \& Equal Workplace Advocates 2021).

A transgender individual has a unique and special gender expression, as they do not conform to the identity usual social expectations in terms of appearance, signals, movements, and others traits (Grant et al., 2011). The transgender community represents a particular type of sub-culture that proposes its standards, customs, qualities, ceremonies, and conventions. The transgender community helps reap the benefits of its current stock of demographic dividends. With the growing number of people in the workforce relative to dependents, economic productivity has a greater chance to improve, especially in developing countries (Shahiduzzaman, 2016). The workplace where employees feel a high sense of inclusivity often leads to a 56 percent increase in job performance and a 50 percent reduction in turnover risk in the developed world (Aguilar, 2020). Moving to the same notion, it can be inferred that the contributions of trans workers need to be recognized in the developing countries' perspectives to make the employees' D\&I experience holistic.

Unfortunately, trans people often experience stigma and discrimination, hostility from others, and pressure to deal with their workplace identities. These experiences can set in motion a host of psychological responses that have devastating consequences for trans individuals' job satisfaction, turnover intentions, and emotional wellbeing (Thoroughgood et al., 2020). Despite the growing awareness of trans individuals' struggles, many employers remain ill-equipped to create trans-friendly policies to support their trans employees. The invisibility and exclusion of the transgender community impose several perils on the organizations to ensure equity and D\&I among employees.

The developing countries like Bangladesh have been experiencing insufficient employment opportunities followed by the skill-gap of the employees and increased dependency ratio (Shahiduzzaman, 2016). To increase the supply of skilled workforce, the inclusion of all categories and genders is vital. Also, according to the report of UN Women (2020), COVID-19 has a substantial implication on the livelihoods of transgender people in Bangladesh as most of them work for the informal sector. Moreover, the Bangladesh government has emphasized safeguarding their rights by declaring them officially as the third gender (TG) (FirstPost, 2013) (Islam 2016) (Aziz and Azhar 2019) (BBC News 2021). Nevertheless, they struggle with social stigma, isolation, negative perception, and workplace discrimination (Sifat, 2020). The patriarchal domination, noncooperative social structures, and religious misconceptions contribute to workplace discrimination (Shoma, 2019) (Hafiz \& Latiff, 2020) (Hafiz, et al., 2021).

The extant literature dedicated to organizational gender diversity emphasizes males and females and often neglects the transgender community (Baggio, 2017). The literature accentuating trans workers' prejudice and discrimination in the workplace is scarce. Hence, there is a clear gap in the extant literature to identify their feeling of inclusion while working in a decent workplace. In order to fill the gap, it is imperative to assess the inclusion experience of the trans workers in the organizations. The research objectives of the study would be twofold:

(i) To investigate the transgender people's inclusion experience in the formal workplace setting; and

(ii) To investigate the transgender people's inclusion experience in the informal workplace setting.

The study selects one of the South-Asian countries, Bangladesh. The reason to select the country's organization is to make the companies realize that transgender people's inclusion experience can play a vital role in promoting their diversity. The study aims to contribute to the Bangladeshi companies that need to create a reputation in the global markets in terms of diversity and inclusion 
and promote innovative products and processes with a divergent workforce, especially in the pandemic era.

The article is organized in the following manner. The next section outlines the pertinent concepts to understand the transgender community of Bangladesh, their present workplace discrimination, and inclusion experience. The following section elaborates on the methodological approach employed. In the following section, the qualitative and quantitative results are analyzed. Then the study findings, implications, and recommendations are discussed. A conclusion and directions of future research wrap up the research.

\section{Transgender community of Bangladesh}

\section{Literature Review}

Bangladesh government has acknowledged the trans community as third gender $(T G)$ and permitted voting registration as a third gender to safeguard their rights (FirstPost, 2013; Anam, 2015; Jebin \& Farhana, 2015; Islam, 2016; Hossain, 2017; Aziz and Azhar, 2019; BBC News, 2021). Unfortunately, by scholars, the trans community are recognized as to the most excluded of the excluded segment (Khan et al., 2009) and remain on the social peripheries (Stenqvist, 2015 and Hossain, 2018). The trans community, in the South-Asian context, is well-known as Hijra, which means cross-dresser or hermaphrodite (Aziz \& Azhar, 2019), subject to socially stigmatized and excluded. They often isolate themselves in self-sufficient and well-stitched groups led by a mentor (Burchardt 2002, Shahzad et al., 2020). They are subject to social and structural prejudice; and face social and organizational discrimination (transphobia) for not fitting into the dominant gender domain (Grant et al., 2011; Mitchell \& Howarth, 2009). The community represents a subculture of gender consisting of maleto-female transgender people, often of working-class backgrounds (Abdullah et al., 2012; Hossain, 2018). According to the transgender rights campaigners, there are 1 million (The Hindu, 2021) to 1.5 million transgender population in Bangladesh. The majority of them face social discrimination and violence, with their crucial survival tool being beggary or harlotry (BBC News, 2021). In neighboring countries such as India and Pakistan, trans individuals experience better treatment at their respective workplaces and earn more than Bangladesh (Bahadur \& Kumar, 2016).

The life of many transgender people is indistinguishably associated with their Hijra community (Hossain, 2018). Recently, transgender community have made some progress in the formal workplace settings, followed by a revolutionary debut of a trans newsreader in a Bangladeshbased TV channel (BBC News, 2021). Despite their strong interest ((Khan et al., 2009), the Bangladeshi transgender people, given their non-conformity to the expected social standards, strive to get and maintain routine jobs and lifestyles (Abdullah et al., 2012; Jebin, 2019). In reality, a handful of transgender people continue employment in civil societies (Aziz \& Azhar, 2019; Hossain, 2018); most of the community serves their mentor, popularly known as a guru, to run their livelihood (Haq, 2015; Stenqvist, 2015). The challenge to access and retain jobs by the TG community in Bangladesh is broadly attributed to stereotyping (Stenqvist, 2015), such as a more feminine attitude that infuses greater social ridicule and physical assaults (Jebin, 2019). Many of them are even considered unfit or unsuitable for the job (Abdullah et al., 2012). Despite this, the key drivers and mitigators of discrimination have not been covered much in the context of Bangladeshi transgender people (Fontana, 2020).

\section{Workplace discrimination}

The 2030 Agenda for Sustainable Development identifies gender as an imperative to providing a "safe, nonviolent, inclusive, and effective" world for all and highlights goals to eradicate inequalities (United Nations Women, 2018). The fourth industrial revolution has been driving the developing world to recruit, deal with health and safety, sense of belongingness, and career progression of workforce minorities, including transgender; the financial adversity of COVID-19 has forced the organizations to cut their diversity initiatives. This situation leads to discrimination, hardship, and injustice for trans employees (Hafiz et al., 2021). Workplace discrimination is one of the most 
common problems, which hinders the exercise of equal employment opportunity and fair treatment (Thomas \& Ely, 2002), and goes against the law of protecting employees' rights (Cox, 2001).

The extant literature has approved that gendered behavior is primarily learned in social and developmental psychology. While sharply distinguished gender roles are taught to males and females from childhood, it is unique, misinterpreted, or ignored for trans individuals. Such situations cause them to be stigmatized and socially devalued, which creates the critical foundation of discrimination against them (Muhr \& Sullivan, 2016). It flows from our mindsets to society to organizations, which, if not destigmatized, may lead to lower self-esteem, social isolation, and drug addiction, or other dysfunctional surviving mechanisms and further detriment the condition of the already overlooked and excluded group. Lombardi et al. (2002) and Yasin, R., \& Jauhar, J. (2018) studied that transgender person is a neglected group in society, and more often, they are the ones who are unable to find jobs and, when employed, find it challenging to sustain their employment because of their non-binary gender identity.

The most common form of discrimination that trans employees experience at work is being harassed or bullied by their coworkers. Having a feeling of "embarrassment to the organization", being a subject of gossip or facing awkward questions, and excluding trans coworkers from social gatherings belittles the trans workers as less human (Beauregard et al., 2021). Discriminatory workplace practices often create a glitch for recruiting and retaining diverse employees with unique mindsets. Brewster et al. (2014) found trans workers experiencing hostility due to their gender orientation in their work environment. In an experimental study, Dray et al. (2020) and Rice et al. (2021) found lower workplace skills and likeability and poorer job performance of a trans worker compared to a regular worker.

The top management team's inability to address prejudicial and stereotyped attitudes sends an indirect yet compelling message to the potential employees and stakeholders about their insensitive reputation as employers in the competitive labor markets (Downey, Van Der Werff, Thomas, \& Plaut, 2015). In the studies of Whittle (2006) and Whittle et al. (2007), the workplaces were found to be more antagonistic to the trans-females than the trans-males. They are commonly fired, harassed, demoted, or pressured to quit by coworkers and management. They are least likely to find support for their identity in the workplace. Nevertheless, social exclusion of this kind may lead trans workers to resentment, discrimination, absenteeism, demoralized work motivation, and lower job commitment, resulting in decreased efficiency, performance, and productivity and increased turnover. Leaving a job may result in future earnings, promotions, and upward mobility, causing them to survive on the streets by beggary and harlotry.

The existing policies and practices are insufficient and less emphasized on transgender people's employment. Also, due to the lack of specific legislation, the group is subjected to much possible discrimination. Many organizations find transgender identities complicated and create a traditional work culture, as they need to espouse themselves to correct social name, pronoun or preferred lounge, toilets, uniform, etc. Megan et al. (2014) found that transgender people are subjected to unfair treatments like verbal abuse and physical and sexual violence; they often become victimized in the workplace, both formal and informal settings. Thus, their inclusion experience is found to be apathetic and discriminatory, as suggested by the literature.

\section{Inclusion experience of Trans workers}

Trans workers are prone to hiding their transgender identity at work as a coping strategy for avoiding discrimination and harassment, but this behavior engenders their psychological anxiety and career aspirations, such as applying for jobs or promotions (Beauregard et al., 2021). Even though increasing participation of organizations in diversity initiatives such as the Corporate Equality Index and the Workplace Equality Index shows a willingness to adopt a more inclusive environment, there is a danger of treating equality as just a 'box-ticking exercise.' Only a tiny percentage of companies that promote themselves as 'highly inclusive' genuinely mean it (Gut et al., 2018). Although the human resource department and top management are the focal points of contact when a transgender employee comes out at work, their role is visible only when they have legal implications. In reality, 
they influence the employee's sense of dignity by ensuring fair treatment and acceptance in the workplace. There is a gap between the expected level of transgender people and the existing corporate policies that are inadequate in addressing the issues of the transgender community.

Diversity \& Inclusion (D\&I) is the capacity and intention to leverage individual differences and commonalities to achieve organizational objectives. D\&I comes hand to hand. Having diversity metrics without ensuring an inclusion experience for their employees' pool on their dashboard only makes the numbers look good without impacting them. Even the best talent will not contribute sustainably to the organization if they feel the inclusion element is missing. Inclusion eventually leads to more perceptible employee engagement and justifies the diversity of talents and ideas. Diversity refers to the variances and resemblances individuals bring to a company, including demographic variations, functional backgrounds, work style, thinking approach, and learning orientation. Inclusion refers to nurturing an organization to be interactive and cooperative to make employees feel welcomed, recognized, and treasured for their capabilities, commitment, and contribution to achieving the organizational objectives. A study by Nkomo (1995) points out that one group of scholars considers diversity as employees differentiating themselves in terms of work, expertise, values, and cognitive capacity besides sexual orientation, physical condition, and education. Another group of researchers argues that diversity results from the discrimination and exclusion of specific subgroups from organizations. Employee characteristics broadly impact organizational performance and sustainability.

Past studies recommended incorporating diversity in the workforce to create a between productivity and competitive advantage, which is even more vital to combat the challenges associated with the post-pandemic business environment (Ashikali et al., 2021; Hafiz et al., 2021). The US Office of Personnel Management proposed a five-pillared construct of an integrated, inclusive workplace, such as fairness, openness, cooperation, support, empowerment (Hur, 2020). Inclusion is a crucial experience for transgender people and is essential to leverage a firm's strength. Through inclusion, they perceive themselves as valued members, fulfill their belongingness needs, and acknowledge uniqueness (Shore et al., 2011). A study by Webster et al. (2018) found that the extent to which the firms exercise such practices and the psychological wellbeing of TG employees are strongly correlated. In another study, Enrica Ruggs et al. (2015) found that implementing transsupportive policies leads to the respondents' frankness about their non-binary gender identities and experience non-discrimination. Therefore, effective diversity and equity practices are vital for the increased productivity of all employees. Herrick et al. (2014) found that various coping strategies and social support can trigger optimistic mental health and increased resilience. Another study showed positive relations between employees' perceptions of a supportive work environment and employees' organizational identification, consistent across gender and ethnic groups (ChrobotMason \& Aramovich, 2013).

\section{Participants and Procedure}

\section{Research Methodology}

The data is collected via a google form survey between January 2021 and June 2021 from the trans workers of an apparel company, a footwear company, a beauty salon, an online food delivery services, and a religious school for the third gender community. The questionnaire was sent to 63 trans workers but was filled and returned to the researchers by 47 respondents. The respondents were carefully chosen using the snowball approach (Souza \& Carrieri, 2015). The snowball sampling method is extensively used for a population with rare traits, and it is tough to choose subjects to assemble them as samples for research.

A focus group discussion was arranged via google meet with seven trans workers from the above organizations. The target population was selected on two criteria: (1) Self-identification as transgender and (2) Employees of an organization. To make the survey easy to understand for some of them, especially from the beauty salon and food-delivery services platforms, the researchers elaborated the research questions in their local language, Bangla. Table 1 represents the demographic profile of the respondents from the sample. 
Table 1: Demographic profile of the respondents

\begin{tabular}{|c|c|}
\hline Elements & Sample $(N=47)$ characteristics \\
\hline Gender Identity & $\begin{array}{c}\text { Trans man: } 32(68.09 \%) \\
\text { Trans woman: } 15(31.91 \%)\end{array}$ \\
\hline Age range & $\begin{array}{c}\text { 16-24: } 16(34.04 \%) \\
\text { 25-34: } 18(38.30 \%) \\
\text { 35-44: } 11(23.40 \%) \\
45 \text { and above: } 2(4.26 \%)\end{array}$ \\
\hline Educational qualification & $\begin{array}{l}\text { SSC or equivalent: } 17(36.17 \%) \\
\text { HSC or equivalent: } 22(46.81 \%) \\
\text { Honors or Equivalent: } 6(12.77 \%) \\
\text { Masters or Equivalent: } 2(4.26 \%)\end{array}$ \\
\hline Industry/ Sector of the sample & $\begin{array}{c}\text { Apparel: } 9(19.15 \%) \\
\text { Food \& Grocery: } 4(8.51 \%) \\
\text { Delivery service: } 11(23.40 \%) \\
\text { Beauty Salon: } 5(10.64 \%) \\
\text { Religious Institution: } 18(38.30 \%)\end{array}$ \\
\hline Position & $\begin{array}{c}\text { Clerk: } 5(10.64 \%) \\
\text { Student: } 18(38.40 \%) \\
\text { Administration: } 2(4.26 \%) \\
\text { Delivery Man: } 11(23.40 \%) \\
\text { Production: } 11(23.40 \%)\end{array}$ \\
\hline Job Location & $\begin{array}{c}\text { Tongi, Dhaka: } 4(8.51 \%) \\
\text { Ashulia, Dhaka: } 5(10.64 \%) \\
\text { Kamrangir Char, Dhaka: } 18(38.30 \%) \\
\text { Uttara, Dhaka: } 11(23.40 \%) \\
\text { Badda, Dhaka: } 4(8.51 \%) \\
\text { Karnaphulli EPZ, Chittagong: } 5(10.64 \%)\end{array}$ \\
\hline
\end{tabular}

The age profile of the respondents was regarded as acceptable, with a majority of the respondents coming from the 25-34 age group, as their average life span ranges from 30-35 years. More transmale respondents are justified by most male employees coming from the labor force instead of their trans-female counterparts. The respondents representing the education level of HSC equivalent reflect their highest presence. Most of the respondents are students or involved in the delivery and production jobs. The religious institution and the delivery company have the majority of the respondents located in the Kamrangir Char area of the Dhaka division of the country. Dhaka and Chittagong are the two major divisions of Bangladesh.

\section{Measures}

The research objective of the study is to examine if workplace discrimination adversely impacts the transgender's inclusion experience. The paper creates a questionnaire and themes for focus group discussion to achieve the objectives. The questions and themes are based on an extensive literature review. The elements of discrimination and inclusion are adopted from the study of Rundall and Vecchietti, 2010). To operationalize the critical variables, the discrimination and inclusion experience of this study, the data collection instrument of choice was closed-ended questions for the survey and open-ended themes for a focus group. This combination will help make surveys more flexible (Gut et al., 2018).

For the quantitative findings, the questionnaire consisted of questions on a feeling of inclusiveness using a 5-point Likert scale (1= Actively included, 2= Mostly included, $3=$ Mostly excluded, 4= Actively excluded, 5= We all continue as before) adapted from Rundall \& Vecchietti (2010). The collected data was then scrutinized, verified, analyzed. Using SPSS 21.0, the data was interpreted through frequency and percentages computed to interpret data to draw accurate findings 
from the research data. To provide a comprehensive analysis, a chi-square test was used. Based on data analysis, findings, conclusions, and recommendations were made. The focus group discussion (FGD) consisted of seven respondents who shared their views on four themes.

While the formal setting in an organization is considered the standard work environment, the informal settings include networks like the grapevine or gossip circles consisting of coworkers and workgroups (Rundall \& Vecchietti, 2010). The information revealed from the questionnaire and FGD can be divided into two broad categories:

i. Workplace discrimination

ii. Inclusion experience.

\section{Results and Analysis}

\section{Quantitative Findings}

\section{Workplace discrimination}

The data shows that over two-thirds of the respondents reported adverse experiences in the workplace, including harassment and, in several cases of abuse. In many cases, experiences of such complaints have led more than half the respondents to change or leave employment. Table 2 (adopted from Rundall \& Vecchietti, 2010) shows their experiences in formal settings.

Table 2: Discrimination experience in the formal settings

\begin{tabular}{|c|c|c|}
\hline Discrimination Type & Frequency & Percentage \\
\hline Have been rejected for additional task & 7 & 14.89 \\
\hline I felt left out while working in a team & 17 & 36.17 \\
\hline Opinion has not been counted in decision-making & 9 & 19.15 \\
\hline Had work-related requests constantly unfulfilled & 8 & 17.02 \\
\hline The contribution was not fairly rewarded & 4 & 8.51 \\
\hline Threatened/forced to leave the job & 2 & 4.26 \\
\hline Total & 47 & 100 \\
\hline Source: Authors
\end{tabular}

Table 3 (adopted from Rundall \& Vecchietti, 2010) shows their experiences in informal settings.

Table 3: Discrimination experience in informal settings

\begin{tabular}{|c|c|c|}
\hline Discrimination Type & Frequency & Percentage \\
\hline Not has been heard & 9 & 19.15 \\
\hline Indirectly reminded of being outcasted & 20 & 42.55 \\
\hline Have been the center of gossip & 5 & 10.64 \\
\hline Have been bullied/ mocked & 10 & 21.28 \\
\hline Faced physical abuse and forced-leaving & 3 & 6.38 \\
\hline Total & 47 & 100 \\
\hline \multicolumn{2}{|c}{ Source: Authors }
\end{tabular}

The trans workers broadly experienced that they could not establish their positions as a contributing team-player and their opinion in the decision-making in the business in the formal business setting (table 2). However, table 3 suggests that in an informal gathering of other colleagues, they had a negative experience as they found themselves in the place of gossip and their voices not heard. However, it is a good sign to the studied organization's D\&I practice that the number of transemployees having experience of abuse and forced leaving is smaller (6.38 percent).

\section{Inclusion experiences}

To analyze the respondents' inclusion and exclusion experiences, the workplace setting has been divided into formal and informal situations. The following table 4 shows the inclusion extent of the respondents in formal and informal settings. 
Table 4: Inclusion experience of the respondents

\begin{tabular}{|c|c|c|}
\hline Workplace Settings & Inclusion extent & Frequency \\
\hline Formal & Actively included & 4 \\
& Mostly included & 6 \\
& Mostly excluded & 11 \\
& Actively excluded & 9 \\
& We all continue as before & 17 \\
\hline Informal & Actively included & 1 \\
& Mostly included & 4 \\
& Mostly excluded & 12 \\
& Actively excluded & 20 \\
& We all continue as before & 10 \\
\hline \multicolumn{2}{|c|}{ Source: Authors }
\end{tabular}

Based on Table 4, the respondents neither feel included in the formal or informal setting but feel that they are being excluded actively (intentionally left out) in the informal or social gatherings of the coworkers. The chi-square analysis (table 5) also confirms the same:

Table 5: Chi-square analysis of inclusion experience

\begin{tabular}{|c|c|c|c|}
\hline Pearson Chi-square & Value & Df & Asymp Sig.(2-sided) \\
\hline Formal Inclusion Experience & 1.367 & 4 & .713 \\
\hline Informal Inclusion Experience & 1.852 & 4 & .604 \\
\hline \multicolumn{4}{|c|}{ Source: Authors }
\end{tabular}

Since the chi-square values are more significant than the chi-square critical value of .05 (i.e., -1.645) for both formal and informal setup, then it can be said that the null hypothesis is rejected. Alternatively, in other words, the inclusion experience is not pleasant to the trans workers' informal and formal workplace setups. They feel that their coworkers mainly do not consider their transgender colleagues as part of their team.

\section{Qualitative Findings}

In the focus group discussion, seven respondents were told to discuss their opinion on if they consider their organization to be trans-inclusive or not. They have shared their opinion in the hybrid language (Bangla and English). A translated version is elaborated below:

Table 6: Opinions on trans-inclusivity of workplace

\begin{tabular}{|l|l|}
\hline $\begin{array}{l}\text { First } \\
\text { Respondent }\end{array}$ & $\begin{array}{l}\text { "I do not think so because my teammates do not value my talents and the contribution I } \\
\text { make, despite our explicit organizational guidelines." }\end{array}$ \\
\hline $\begin{array}{l}\text { Second } \\
\text { Respondent }\end{array}$ & $\begin{array}{l}\text { "Our boss has made it clear that harassment will not be tolerated in this organization, } \\
\text { regardless of who you are. Everybody is afraid of the boss. I do not care if the colleagues } \\
\text { speak something on my back". }\end{array}$ \\
\hline $\begin{array}{l}\text { Third } \\
\text { Respondent }\end{array}$ & "A strong no, because my coworkers make me feel uncomfortable, especially while \\
\hline $\begin{array}{l}\text { Fourth } \\
\text { traveling and meeting other clients." }\end{array}$ & "I do not think my organization is trans-inclusive as I face obstacles in my career \\
\hline $\begin{array}{l}\text { Fifth } \\
\text { Respondent }\end{array}$ & "I am indifferent because I know exactly where and how to report harassment or \\
\hline $\begin{array}{l}\text { Sixth } \\
\text { Respondent }\end{array}$ & "Most of the time, I do not like when my supervisor and colleagues pressure me to hide \\
\hline $\begin{array}{l}\text { Seventh identity to fit in at work." } \\
\text { Respondent }\end{array}$ & "My organization seems to value our opinions, but my team is not genuinely interested to \\
hear us."
\end{tabular}


"Whether the transgender group faces glass ceiling across the organization or not" was the second theme of discussion. It was found that out of seven respondents, three of the respondents had a promotion in their present company, where they were openly known to be transgender people. However, two of them were denied promotion, and one was explicitly demoted because of their nonbinary gender identity. They also confirmed that terminating them on being transgender is just a boxticking exercise. Five of them have lost their previous job, are consistent in their current role, and managed a promotion. Most believe that such behavior would mean that organizations do not want trans workers to represent them.

The third theme was to explore their perspectives on Organizational Diversity. One of them suggested that diversity values employees of different talents and skills. Employees of all cultures and sexual orientations will be respected when the concept of diversity is implemented. Another respondent added that prioritizing diversity will help create a more vital organization. They also believed that when employees from all backgrounds have equal opportunities to upgrade themselves, organizational diversity is exercised fairness and equity.

The final theme discussed in the session was that most (four out of seven) did not have any such training if the respondents received diversity training. One of them advocated that it is about proactive recognition. Another person added that embracing differences is essential for promoting business growth. They also agreed that diversity in employees could drive diversity of ideas.

\section{Discussion and Recommendations}

Various International Human Rights agencies such as the Universal Declaration of Human Rights (UDHR) of the United Nations, International Covenant on Civil and Political Rights (ICCPR), and The International Covenant on Economic, Social and Cultural Rights (ICESCR) have been working to establish and implement transgender people's human rights on education in developing countries, including Bangladesh. Despite their efforts, the trans workers live on the periphery of organizations and remain isolated (Islam, 2016). In response to COVID-19, the UN high commissioner for human rights and the World Health Organizations have taken initiatives, and the Prime Minister of Bangladesh called for special attention and relief for transgender people. The government strives to apply an inclusive approach to manage the crisis to ensure that the most vulnerable communities survive (Knight, 2022). The finance minister of Bangladesh has proposed that businesses recruiting $10 \%$ of the total workforce or having at least 100 trans staff would be eligible for a tax rebate (AlJazeera, 2021) (Hindu, 2021). Organizations should proactively integrate specialized policies and practices in their formal and informal settings favorable for transgender individuals by protecting their rights and increasing the acceptance of trans-coworkers. A trans-friendly work environment can enhance the ignored employee segment's inclusion experience and job satisfaction.

When all the employees in an organization accept an individual's gender identity, a greater inclusion experience is stimulated. Organizational diversity will be established if the organizations develop an all-inclusive environment with heterogeneous employees' skills, attitudes, and knowledge to optimize problem-solving and decision-making in organizations (Thomas, 1991). Gender-identityspecific de-stigmatization practices may help steer the trans-employees in their involvement towards creating a trans-inclusive workplace (Whittle 2002). Trans-inclusive cultures are six times more innovative and productive (Lead Inclusively, 2021).

An inclusive work environment will also lead to process innovation and improved business practices in the age of technology and modern equipment. Inclusive innovation is fostered when employees feel that their organization empowers them to experiment with diverse ideas in the business environment characterized by learning agility without accusing their ideas of failure. Impactful innovation is critical to organizational success in the dynamic business environment, as they are better to leverage the diverse perspectives to innovate new products and enhance user experiences. If the inclusion innovation can be combined appropriately with the D\&I experience of the employees of an organization, it will produce process innovation.

$$
\text { Inclusion Innovation }+\mathrm{D} \& \mathrm{I}=\text { Process Innovation }
$$


Through implementing this radically new method to perform its business operations, process innovation primarily impacts the organization and enhances competitive advantage. Process innovation at trans-inclusive organizations will lead to value addition among all the employees, stakeholders, and organization itself with increased efficiency, productivity, and other key performance indicators (KPIs) and ensures growth of an organization. In addition, if the D\&I experience of the employees is seen through the lens of learning, it can be acknowledged with maximum efficiency. This paradigm requires organizations to integrate the diverse skillsets by promoting differences and creating a learning environment where all employees can apply their diverse inputs and realize their full potential (Thomas \& Ely, 2002).

The concepts of equal opportunities owe much to the awareness of the issues of D\&I that were brought about by the study. The study's findings will contribute to the development of D\&I for best organizational practice. To ensure equal treatment to all the employees, a holistic involvement by the top management and human resources departments needs to be ensured (Gut et al., 2018). A diversity manager can be hired to oversee diversity training and upskilling to make all the employees more familiar with transgender issues besides gender, race, or sexual orientation. It is also crucial to train the trainer to teach the employees to be deferential towards trans workers. Moreover, as the COVID-19 era continues to reshape the businesses' modus operandi, it is vital for the organizations to sustain D\&I to support the trans workers (Out \& Equal Workplace Advocates, 2021). In order to make a move towards making a social impact, the study proposes recommendations to the organizations to implement the following measures:

- To discourage exclusionary behavior to all employees, regardless of formal and informal platforms;

- To use the necessary tool, equipment, language, and technology that is accessible to all;

- To support all employees to achieve their work-life balance and improve their job satisfaction;

- To learn from the diverse perspectives of all employees to accelerate inclusive innovation;

- To demonstrate reasonable accommodations to all employees to ensure access to paid leave and mental and financial support policies during the COVID-19 pandemic.

They can also initiate and implement professional development programs, diversity-focused mentoring programs, employee-resource groups or networking groups, and affiliations to various diversity-focused organizations.

\section{Research Limitations and Future Study Directions}

This study has some limitations. Based on the findings of the study of Muhr and Sullivan (2016), trans workers face heterogeneous and context-dependent D\&I experiences at workplaces. The study considers only the organizations cooperating to reveal their employees' contact. Therefore, more organizations, including small businesses, could be considered for future research. Also, the country's focus is Bangladesh. To address the workplace issues of transgender people and offer customized solutions, the frameworks elaborating organizational practices of other developing countries can be studied. Last but not least, based on the study's findings, the researchers suggest future studies to investigate the impact of socio-economic exclusion of the transgender community during the postpandemic era.

\section{Conclusions}

The study has highlighted the multifaceted issues faced by the transgender community, which are the roots of their exclusion experience. Innovation will emerge through inclusion, followed by diverse ideas being heard, valued, tested, and prototyped. Organizations mastering D\&I have a better chance of attracting and retaining the best talents. In their turn, a diverse pool of talents can become a unique competitive advantage for a company. A more diverse workforce can be a potential source of strength for a company as through this tool, they can enhance their understanding of the diverse needs of 
diverse sets of customers. The D\&I achievement can be an effective predictor of organizational sustainability.

This article offers valuable and practical suggestions for organizations aiming to manage diversity better and reduce discrimination against transgender people. The typology of the pragmatic approach presented in this article, such as instilling process innovation through establishing D\&I experience for the employees, demonstrates that organizations need to operate outside the box. The study's findings are expected to help the government, NGOs, Counsellors, policymakers, psychologists, and social workers take measures to work towards the upliftment and empowerment of this minority community. It is believed that incorporating positive D\&I experience will increase the knowledge and awareness of trans individuals and develop the skills and motivations for creating opportunities for them.

\section{Acknowledgment}

The authors are grateful to the honorable editorial board members and anonymous reviewers for their guidance. Special thanks to Dr. Md. Asadul Islam, Assistant Professor of BRAC University, for his encouragement.

\section{References}

Abdullah, M. A., Basharat, Z., Kamal, B., Sattar, N. Y., Hassan, Z. F., Jan, A. D., \& Shafqat, A. (2012). "Is social exclusion pushing the Pakistani Hijras (transgender people) towards commercial sex work? A qualitative study." BMC International Health and Human Rights, 12(1), 32-41. https://doi.org/10.1186/1472-698X-12-32

Aguilar, D. (2021). Think with Google. Retrieved from Are your inclusion efforts excluding the transgender and gender nonconforming community?: https://www .thinkwithgoogle.com/future-of-marketing/management-andculture/diversity-and-inclusion/transgender-gender-nonconforming-communityinclusivity/

AlJazeera. 2021. Tax rebate for Bangladesh companies hiring transgender people. June 4. https://www .aljazeera.com/news/2021/6/4/tax-rebate-for-bangladesh-companieshiring-transgender-people.

Anam, T. (2015). Transgender rights, Bangladesh style. New York Times. Retrieved from https:/www.nytimes.com/2015/07/03/opinion/ tahmina-anam-transgender-rightsBangladesh-labannya-hijra.html

Aziz, A., \& Azhar, S. (2019). 'Social exclusion and official recognition of hijra in Bangladesh'. Journal of Research on Women and Gender, 9, 3-19.

BBC News. 2021. Bangladesh's first transgender news reader makes debut. March 9. https://www.bbc.com/news/world-asia-56332730.

Bahadur, A., \& Kumar, K. K. (2016). I am the man for the job: The challenges of coming out as a female-to-male transgender person in the Indian organizational space. In T. Köllen (Ed.), Sexual orientation and transgender issues in organizations 43-62. Zurich, Switzerland: Springer International Publishing.

Baggio, M. (2017). 'About the relation between transgender people and the organizations: new subjects for organizational diversity studies. REGE - Revista de Gestão 24, 360370. http://dx.doi.org/10.1016/j.rege.2017.02.001

Beauregard, T. A., Booth, J. E., \& Whiley, L. A. (2021). Transgender employees: Workplace impacts on health and wellbeing. In J. Hassard \& L. D. Torres (Eds.), Aligning perspectives in gender mainstreaming: Gender, health, safety and wellbeing (pp. 177- 196). Springer. 
Brewster, M. E., Velez, B. L., Mennicke, A., \& Tebbe, E. (2014). Voices from beyond: A thematic content analysis of transgender employees' workplace experiences. Psychology of Sexual Orientation and Gender Diversity, 1(2), 159-169.

Burchardt, T., Le Grand, J., \& Piachaud, D. (2002). Degrees of Exclusion: Developing a Dynamic, Multidimensional Measure. In Hills, J. Le Grand, J. and Piachaud, D. Understanding Social Exclusion. Oxford University Press. https://gsdrc.org/topicguides/social-exclusion/identifying-exclusion/identifying-and-measuring-socialexclusion/

Cox, T. (2001). Creating the multicultural organization: A strategy for capturing the power of diversity. San Francisco: Jossey-Bass.

Dray, K. K., Smith, V. R., Kostecki, T. P., Sabat, I. E., \& Thomson, C. R. (2020). Moving beyond the gender binary: Examining workplace perceptions of nonbinary and transgender employees. Gender, Work, \& Organizations, 27, 1181-1191.

Downey, S. N., Van Der Werff, L., Thomas, K., \& Plaut, V. C. (2015). 'The role of diversity practices and inclusion in promoting trust and employee engagement'. Journal of Applied Social Psychology, 45(1), 35-44.

FirstPost. 2013. Transgenders officially a 'third gender' in Bangladesh. November 14. https://www .firstpost.com/world/transgenders-officially-a-third-gender-inbangladesh-1229221.html/amp.

Fontana E. (2020). 'Managing diversity through transgender inclusion in developing countries: A collaborative corporate social responsibility initiative from Bangladesh'. Corporate Social Responsibility Environment Management 27, 25482562. https://doi.org/10.1002/csr.1975

Grant, J. M., Mottet, L. A., \& Tanis, J. (2011). Injustice at every turn - A report of the National Transgender Discrimination Survey. Washington: The National Gay and Lesbian Task Force and the National Center for Transgender Equality.

Gut, T., Arevshatian, L., \& Beauregard, T. A. (2018). 'HRM and the case of transgender workers: A complex landscape of limited HRM 'know how' with some pockets of good practice'. Human Resource Management International Digest, 26(2), 7-11. https://doi.org/10.1108/HRMID-06-2017-0121.

Hafiz, N., Latif, A.S.A. (2020). Entrepreneurship as a Sustainable Solution for the Female Graduates in the SME Sector of Bangladesh. Journal of Business and Social Review in Emerging Economies, 6(2) 483-492.

Hafiz, Nusrat, Samiha N. Majumdar, Mukit Anis, Ahmad Shaharudin Abdul Latiff, and Sazali Abd Wahab. 2021. "An Assessment of Diversity, Equity, and Inclusion Management Practices in the Small Businesses of Bangladesh." International Conference on Business and Management (ICBM). Dhaka, Bangladesh: BRAC University.

Haq, K. (2015). 'The Hijra comes in from the heat and dust'. Wasafiri, 40(3), 3-7. https://doi.org/10.1080/02690055.2015.1068982

Herrick, A. L., Egan, J. E., Coulter, R. W., Friedman, M. R., \& Stall, R. (2014). 'Raising sexual minority youths' health levels by incorporating resiliencies into health promotion efforts.' American journal of public health, 104(2), 206-210. https://doi.org/10.2105/AJPH.2013.301546

Hindu, The. 2021. Proposal for tax breaks to companies hiring transgender employees in Bangladesh parliament. June 9. https://www .thehindu.com/news/international/proposal-for-tax-breaks-to- 
companies-hiring-transgender-employees-in-bangladeshparliament/article34766877.ece.

Hossain, A. (2017). 'The paradox of recognition: Hijra, third gender and sexual rights in Bangladesh'. Culture, Health \& Sexuality, 19(12), 1418-1431. https://doi.org/10.1080/13691058.2017.1317831

Hossain, A. (2018). 'De-indianizing Hijra: Intraregional effacements and inequalities in South Asian queer space'. Transgender Studies Quarterly, 5(3), 321-331. https://doi.org/10.1215/23289252-6900710

Hur, H. (2020). 'The role of inclusive work environment practices in promoting LGBT employee job satisfaction and commitment'. Public Money \& Management, 40(6), 426-436, https://doi.org/10.1080/09540962.2019.1681640

Islam, Md. Akramul. 2016. "Right to Education of the Third Gender of Bangladesh: AN overview." IOSR Journal of Humanities and Social Science, 21(9): 29-34.

Jebin, L. (2019). 'Status of transgender people in Bangladesh: A socio-economic analysis. South Asian Journal of Policy and Governance, 42(1), 49-63.

Jebin, L., \& Farhana, U. (2015). 'The rights of Hijra in Bangladesh: An overview'. Journal of Nazrul University, 3(1\&2), 1-9. https://ssrn.com/abstract=3028057

Khan, S. I., Hussain, M. I., Parveen, S., Bhuiyan, M. I., Gourab, G., Sarker, G. F., ... Sikder, J. (2009). 'Living on the extreme margin: Social exclusion of the transgender population (Hijra) in Bangladesh'. Journal of Health, Population, and Nutrition 27 (4), 441-451. https://doi.org/10.3329/jhpn.v27i4.3388

Khan, S. (2016). Reaping benefits of demographic dividend. February 25. https://thefinancialexpress.com.bd/views/reaping-benefits-of-demographicdividend.

Knight, K. (2022). Human Rights Watch. https://www.hrw.org/news/2020/05/08/bangladesh-should-support-hijra-transunder-covid-19.

Lead Inclusively- Culture of Innovation. (2021). How Inclusion Can Drive an Innovation Culture in Your Company, from https://leadinclusively.com/2019/05/02/culture-ofinclusion/

Lombardi, E. L., Wilchins, R. A., Priesing, D., \& Malouf. D. (2002). 'Gender violence: Transgender experiences with violence and discrimination. Journal of Homosexuality, 42(1), 89-101. https://doi.org/10.1300/J082v42n01_05

Megan, L. C., Vaughan, M. D., Rodriguez, E., \& Shmerler, D. (2014). 'Working With LGBT Individuals: Incorporating Positive Psychology into Training and Practice'. Psychology of Sexual Orientation and Gender Diversity, 1(4), 335-347. https://doi.org/10.1037/sgd0000064

Mitchell, M., \& Howarth, C. (2009). Trans research review. Manchester: Equality and Human Rights Commission.

Muhr, S., \& Sullivan, K. R. (2016). 'Situated transgressiveness: Exploring one transwoman's lived experiences across three situated contexts'. Gender, Work and Organization, 23(1), 52-70. https://doi.org/10.1111/gwao.12093

Nkomo, S. M. (1995). Identities and the complexity of diversity. In S. E. Jackson (Ed.), diversity in work teams: Research paradigms for a changing workplace. Washington, DC: American Psychological Association. 247-253

Out \& Equal Workplace Advocates. 2021. LGBT Employees and the COVID-19 Pandemic. https://outandequal.org/covid19-lgbtq/. 
Rice, Lindsay, Joseph M. Currin, Hannah R. Snidman, Amelia E. Evans, and Taylor Cameron D. . (2021). "Examining the Perception of Work-Related Skills for Transgender Employees." Gender Issues. doi:10.1007/s12147-021-09278-3.

Ruggs, E. N., Martinez, L. R., Hebl, M. R., \& Law, C. L. (2015). 'Workplace “trans”-actions: How organizations, coworkers, and individual openness influence perceived gender identity discrimination. Psychology of Sexual Orientation and Gender Diversity, 2 (4),404-412. https://doi.org/10.1037/sgd0000112

Rundall, E. \& Vecchietti, V. G. (2010). 'Transsexual people in UK workplaces: an analysis of trans-men's and transwomen's experiences,' unpublished thesis, Oxford Brookes University

Sifat, R. I. (2020). "The effect of COVID-19 on Hijra (Third Gender) people in Bangladesh." The Lancet Psychiatry 7 (12). doi:10.1016/S2215-0366(20)30464-8.

Shahzad, M., Bhutta, M., Khan, S., Rafiq, N., \& Ramzan, S. (2020). 'Social Exclusion of Aged Transgender in Pakistan: A Case Study of District Rawalpindi'. International Journal of Psychosocial Rehabilitation, 24(3). https://doi.org/10.37200/IJPR/V24I3/PR2020301

Shoma, C. D. (2019). Gender is a Human Rights Issue: The Case of Women's Entrepreneurship Development in the Small and Medium Enterprise Sector of Bangladesh. Journal of International Women's Studies, 20(7), 13-34.

Shore, L. M., Rande, A. E., Chung, B. G., Dean, M. A., Ehrhart, K. H., \& Singh, G. (2011). 'Inclusion and diversity in workgroups: A review and model for future research. Journal of Management, 37(4), 1262-1289.

Souza, E. M. d., \& Carrieri, A. d. P. (2015). 'When invisibility is impossible: Body, subjectivity, and labor among travesties and transsexuals. Journal of Workplace Rights, 5 (2), 1-11.

Stenqvist, T. (2015). The social struggle of being Hijra in Bangladesh: Cultural aspiration between inclusion and illegitimacy. Malmö, Sweden: Malmö University.

Thanem, T., \& Wallenberg, L. (2016). 'Just doing gender? Transvestism and the power of undergoing gender in everyday life and work'. Organization: The Critical Journal of Organization, Theory, and Society, 23(2), 250-271.

Thomas, D. A., \& Ely, R. J. (2002). Making differences matter: A new paradigm for managing diversity. Harvard business review. USA: Harvard Business School Press.

Thomas, R. RJ (1991). Beyond race and gender: Unleashing the power of your total workforce by managing Diversity: AMACOM books.

Thoroughgood, C., Sawyer, K., \& Webster, J. (2020, March-April). LGBT Rights / Creating a Trans-Inclusive Workplace. Retrieved from Harvard Business Review: https://hbr.org/2020/03/creating-a-trans-inclusive-workplace

United Nations Women (2018). Turning promises into action: Gender equality in the 2030 Agenda for Sustainable Development. Retrieved from http://www.unwomen.org//media/headquarters/attachments/sections/library/publications/2018/sdgreportsummary-gender-equality-in-the-2030-agenda-for-sustainable-development2018- en.pdf?la=en\&vs $=949$

UN Women. (2020). COVID-19 Bangladesh Rapid Gender Analysis. GENDER IN HUMANITARIAN ACTION (GIHA) WORKING GROUP.

Webster J.R., Adams G.A., Maranto C.L., Beehr T.A. (2018). "Dirty” Workplace Politics and Well-Being: The Role of Gender'. Psychology of Women Quarterly. 42 (3), 361377. doi:10.1177/0361684318769909 
Whittle, S. (2002). Respect and Equality: Transsexual and Transgender Rights, London: Cavendish Publishing Limited.

Whittle, S. (2006). 'Foreword,' in S. Stryker and S. Whittle (eds). The Transgender Studies Reader, New York: Routledge.

Whittle, S., Turner, L. and Al-Alami, M. (2007). 'Engendered penalties: trans-gender and transsexual people's experiences of inequality and discrimination,' The Equalities Review. http://www.pfc.org.uk/fi les/EngenderedPenalties.pdf.

Yasin, R., \& Jauhar, J. (2018). 'Discrimination with Trans Genders, A pathway for them to Prostitution'. International Journal of Academic Research in Business and Social Sciences, 8(4), 493-499. 